\title{
Which organ should be considered a reference in diffusion weighted imaging of the abdomen?: The reproducibility of ADC measurements of the spleen and the renal cortex on a 1.5T MR
}

\author{
Aleksander Pawluś1, 2, A-F, Kinga Szymańska1, B-F, Mateusz Łasecki ${ }^{1,2, ~ B, C, ~ E, ~ F, ~ J o a n n a ~ B l a d o w s k a ~ 2, ~ 3, ~ D-F, ~}$ \\ Dąbrówka Sokołowska-Dąbek, 2, A-C, E, F, Małgorzata Szumarska-Czech², 2, B, C, E, Krzyszztof Kaczorowski², (-F, \\ Bartosz D. Markiewicz, D-F, Krzysztof Dudek ${ }^{5, C, E, F}$, Urszula Zaleska-Dorobisz', 2, A-F \\ ${ }^{1}$ Department of General and Pediatric Radiology, Independent Public Clinical Hospital No. 1, Wrocław, Poland \\ 2 Department of Radiology, Wroclaw Medical University, Poland \\ ${ }^{3}$ Department of General Radiology, Interventional Radiology and Neuroradiology, Wroclaw Medical University, Poland \\ ${ }^{4}$ Medical University of Silesia, Katowice, Poland \\ ${ }^{5}$ Faculty of Natural Sciences and Technology, Karkonosze College, Jelenia Góra, Poland \\ A - research concept and design; $B$ - collection and/or assembly of data; $C$ - data analysis and interpretation; \\ $D$ - writing the article; $E$ - critical revision of the article; $F$ - final approval of article
}

Address for correspondence

Aleksander Pawlus

E-mail: apawlus@wp.pl

Funding sources

None declared

Conflict of interest

None declared

Received on June 16, 2015

Revised on November 1, 2015

Accepted on December 4, 2015

DOI

$10.17219 /$ acem $/ 60877$

Copyright

Copyright by Author(s)

This is an article distributed under the terms of the

Creative Commons Attribution Non-Commercial License

(http://creativecommons.org/licenses/by-nc-nd/4.0/)

\section{Abstract}

Background. Diffusion weighted imaging (DWI) is a useful tool for the evaluation of focal lesions in the liver or kidneys, as well as for the diagnosis and assessment of the liver fibrosis process. Some reports show that the spleen and kidneys may serve as reference organs in the staging of liver fibrosis or the evaluation of focal liver lesions.

Objectives. The aim of the study was to determine whether the spleen and renal cortex can be used as reference organs in the DWI technique.

Material and methods. The study group included 36 patients with no liver, spleen or renal pathologies and without any infections or hematologic disease. All the examinations were performed using a 1.5T MR unit with a conventional phased array body coil. Image interpretation and apparent diffusion coefficient (ADC) measurements were done by 3 experienced radiologists.

Results. There was a statistically significant difference between the ADC values noted by 2 of the examiners in the upper/middle and lower part of the spleen parenchyma. There were no statistically significant differences between the ADC values obtained by all 3 examiners in all the parts of each kidney. There were no statistically significant differences between the examiners' ADC values for the spleen and kidneys. The mean $A D C$ values for the left kidney showed the highest measurement reproducibility.

Conclusions. The study showed that the renal cortex seems to be an appropriate region for performing reference $A D C$ measurements. Further studies on a larger group of patients and using various DWI protocols should be performed to ascertain the best conditions for maximizing the reproducibility of ADC measurements.

Key words: magnetic resonance imaging (MRI), diffusion weighted MRI, apparent diffusion coefficient, spleen, renal cortex 
Diffusion-weighted magnetic resonance (DW-MR) is a technique in which image contrast reflects in vivo changes in the motion of water molecules (Brownian motion) in tissues. ${ }^{1}$ It has been used for many years in neuroradiology for detecting acute strokes at their early stage, before ischemic lesions are visible on other magnetic resonance (MR) sequences or computed tomography (CT) scans. ${ }^{2}$ Over the few last years it has also been successfully applied to breast and prostate imaging to differentiate between benign and malignant tumors. ${ }^{2-4}$

A supplemental tool in diffusion weighted imaging (DWI) is the apparent diffusion coefficient (ADC) map, acquired by post-processing of the DWI images obtained. ADC allows for the definition of diffusion parameters quantitatively (in $\mathrm{mm}^{\wedge} 2 / \mathrm{s}$ ). ${ }^{1}$

In recent years researchers have tried to find new clinical applications for DWI in diagnosing abdomen pathologies. At present, the usefulness of this method has been established for detection and differentiation within focal lesions in the liver or in kidneys. ${ }^{5-7}$ A very promising application of DWI, especially ADC maps, is diagnosing and assessing the liver fibrosis process. ${ }^{8,9}$ Recent reports show that the spleen and kidneys can serve as reference organs in assessing the stage of liver fibrosis or evaluation of focal liver lesions. ${ }^{10,11}$

However, the technique has some limitations, such as poor image resolution, including a low signal to noise ratio (SNR), and low reproducibility in ADC value measurements. ${ }^{5}$

The aim of the current study was to determine whether the spleen and renal cortex can serve as reference organs in DWI examinations, including ADC maps.

\section{Material and methods}

\section{Study population}

MR examinations of the abdomen performed at Independent Public Clinical Hospital No. 1 (Wrocław, Poland) in the years 2013-2014 were retrospectively analyzed. Patients with liver, spleen and renal pathologies, as well as patients with infection or hematologic diseases, were excluded from the study group. Examinations containing motion artifacts were also rejected. Patients with single renal cysts (2 or fewer in one kidney, with a diameter under $10 \mathrm{~mm}$ ) were included in the study. Based on these criteria a population of 36 patients (Table 1) was selected. Of these 36 patients, 19 were diagnosed with adrenal adenoma; in 7 patients adrenal adenoma was suspected based on ultrasound examination but was not confirmed on MR; 5 patients were suspected of liver focal lesions, excluded on MR; 5 presented an increased level of carcinoembryonic antigen following colon cancer treatment with no pathology on MR.

The study was approved by the ethics committee of Wroclaw Medical University (KB-216/2015).
Table 1. Basic data about the study group

\begin{tabular}{|l|c|}
\multicolumn{1}{|c|}{ Parameter } & Value \\
\hline Number of participants & 36 \\
\hline Number of men* & $14(39)$ \\
\hline Number of women* & $22(61)$ \\
\hline Age ${ }^{1}$ & $33.5(36.75)$ \\
\hline Age range & $18-84$ \\
\hline Men's age & $31.5(29)$ \\
\hline Women's age & $24.5(40)$ \\
\hline
\end{tabular}

* percentage ratio in brackets; ${ }^{1}$ Median; IQR in brackets.

Table 2. The homogeneity of ADC values within the examined organ (Friedman's ANOVA)

\begin{tabular}{|c|c|c|c|c|}
\hline Investigator & $x^{2}$ & $\mathrm{~N}$ & df & $p$-value \\
\hline \multicolumn{5}{|c|}{ Spleen } \\
\hline Radiologist 1 & 8.53 & 36 & 2 & 0.014 \\
\hline Radiologist 2 & 6.08 & 36 & 2 & 0.048 \\
\hline Radiologist 3 & 3.17 & 36 & 2 & 0.205 \\
\hline \multicolumn{5}{|c|}{ Right kidney } \\
\hline Radiologist 1 & 2.21 & 36 & 2 & 0.331 \\
\hline Radiologist 2 & 1.58 & 36 & 2 & 0.454 \\
\hline Radiologist 3 & 1.06 & 36 & 2 & 0.590 \\
\hline \multicolumn{5}{|c|}{ Left kidney } \\
\hline Radiologist 1 & 0.18 & 36 & 2 & 0.912 \\
\hline Radiologist 2 & 2.78 & 36 & 2 & 0.249 \\
\hline Radiologist 3 & 1.56 & 36 & 2 & 0.459 \\
\hline
\end{tabular}

\section{MR protocol}

All the examinations were performed using a Siemens Avanto 1.5T MR unit (Siemens Medical Solutions, Erlangen, Germany) with a conventional phased array body coil.

DWI was performed using a standard protocol, namely single-shot spin-echo-planar imaging (EPI) in the axial plane, with the following parameters: TR 5200-6000 ms, TE $72 \mathrm{~ms}$, voxel size $2 \times 2 \times 5$, Bw $1448 \mathrm{~Hz} / \mathrm{px}$, b values 50 , 400 and 800,30 slices, duration time $\sim 6 \mathrm{~min}$. 

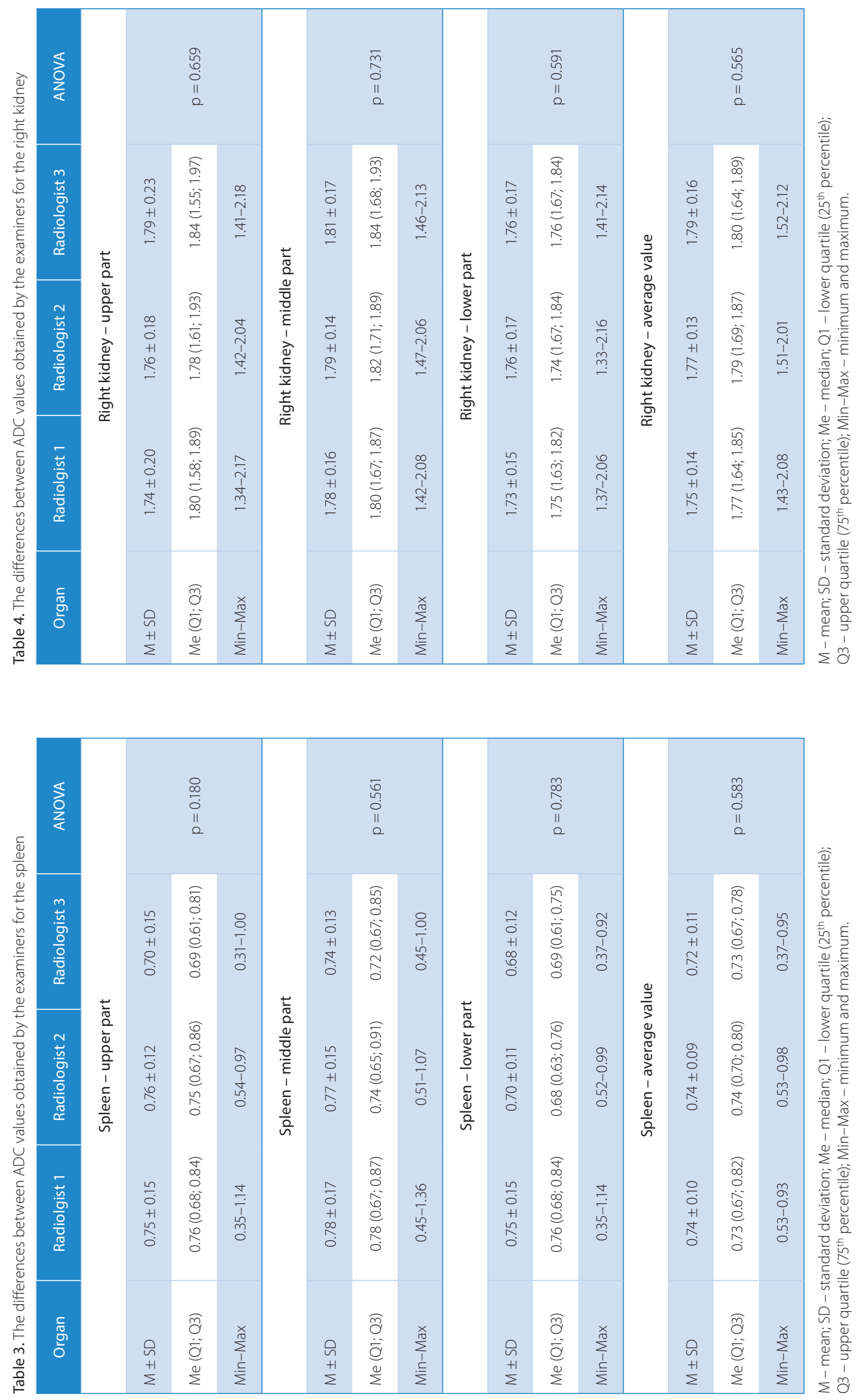
Table 5. The differences between ADC values obtained by the examiners for the left kidney

\begin{tabular}{|c|c|c|c|c|}
\hline Organ & Radiolgist 1 & Radiologist 2 & Radiologist 3 & ANOVA \\
\hline \multicolumn{5}{|c|}{ Left kidney - upper part } \\
\hline$M \pm S D$ & $1.78 \pm 0.17$ & $1.75 \pm 0.18$ & $1.77 \pm 0.20$ & \multirow{3}{*}{$p=0.853$} \\
\hline Me (Q1; Q3) & $1.78(1.63 ; 1.90)$ & $1.76(1.60 ; 1.85)$ & $1.76(1.60 ; 1.92)$ & \\
\hline Min-Max & $1.49-2.16$ & $1.49-2.18$ & $1.44-2.28$ & \\
\hline \multicolumn{5}{|c|}{ Left kidney - middle part } \\
\hline$M \pm S D$ & $1.80 \pm 0.14$ & $1.78 \pm 0.12$ & $1.79 \pm 0.14$ & \multirow{3}{*}{$p=0.937$} \\
\hline Me (Q1; Q3) & $1.79(1.66 ; 1.92)$ & $1.77(1.70 ; 1.88)$ & $1.76(1.69 ; 1.89)$ & \\
\hline Min-Max & $1.56-2.04$ & $1.57-2.06$ & $1.56-2.18$ & \\
\hline \multicolumn{5}{|c|}{ Left kidney - lower part } \\
\hline$M \pm S D$ & $1.80 \pm 0.12$ & $1.81 \pm 0.13$ & $1.80 \pm 0.16$ & \multirow{3}{*}{$p=0.968$} \\
\hline Me (Q1; Q3) & $1.82(1.74 ; 1.86)$ & $1.82(1.75 ; 1.89)$ & $1.81(1.68 ; 1.92)$ & \\
\hline Min-Max & $1.56-2.06$ & $1.46-2.14$ & $1.52-2.17$ & \\
\hline \multicolumn{5}{|c|}{ Left kidney - average value } \\
\hline$M \pm S D$ & $1.79 \pm 0.12$ & $1.78 \pm 0.11$ & $1.79 \pm 0.14$ & \multirow{3}{*}{$p=0.956$} \\
\hline Me (Q1; Q3) & $1.81(1.67 ; 1.88)$ & $1.78(1.70 ; 1.86)$ & $1.78(1.67 ; 1.90)$ & \\
\hline Min-Max & $1.59-2.08$ & $1.60-2.05$ & $1.58-2.08$ & \\
\hline
\end{tabular}

M - mean; SD - standard deviation; Me - median; Q1 - lower quartile (25 th percentile);

Q3 - upper quartile (75 th percentile); Min-Max - minimum and maximum.

\section{Statistical analysis}

The statistical analysis of the data was conducted using STATISTICA v. 10 software (StatSoft Inc., Tulsa, USA). Friedman's ANOVA test was used to evaluate the homogeneity of the ADC values within the examined organ (spleen or kidney). The ANOVA test was chosen to determine the differences between the ADC values obtained by the 3 examiners.

The reproducibility of the measurements obtained was assessed using Pearson's correlation coefficient and the Bland-Altman method.

\section{Results}

\section{Variability in ADC values}

There was a statistically significant difference between the ADC values noted by 2 of the examiners in the upper/ middle and lower part of spleen parenchyma (Table 2). There were no statistically significant differences between the ADC values obtained by all 3 examiners in all the parts of each kidney.

\section{Difference between mean $A D C$ values among examiners}

There were no statistically significant differences between the ADC values noted by the examiners for the spleen and kid-

\section{ADC quantification}

To obtain ADC maps using all $3 \mathrm{~b}$ values (50, 400 and $800 \mathrm{~mm}^{2} / \mathrm{s}$ ), dedicated standard software was used on a Syngo workstation (Siemens Medical Solutions, Erlangen, Germany). ADC measurements were performed by 3 experienced radiologists (with 15, 10 and 7 years of experience in abdominal imaging) using the Syngo.via workstation.

Circular regions of interest (ROIs) were placed on the upper, middle and lower parts of the spleen and renal cortex (3 ROIs per organ: the spleen and each kidney). The examiners were allowed to choose the place of the measurement and the size of the ROIs, but they were asked to place the ROIs in the areas of the most homogenous signal intensity in their assessment. Care was taken to avoid areas of artifacts, the major vessels in the spleen, cysts in the kidneys and capsules. The ROIs used in the analysis were from $1 \mathrm{~cm}$ to $1.7 \mathrm{~cm}$ in size for the spleen, and from $0.4 \mathrm{~cm}$ to $0.9 \mathrm{~cm}$ for the kidneys. neys (Tables 3-5). A diagram analysis revealed lower ADC values noted by the $3^{\text {rd }}$ examiner in each part of the spleen; the difference was not statistically significant, and the same dependence was not observed in the ADC values for the kidneys. Moreover, it was found that the results obtained by the $3^{\text {rd }}$ examiner showed the largest scattering.

\section{ADC reproducibility}

Significant Pearson correlation coefficients (for all 3 examiners) were calculated for the ADC values of the left kidney (all parts), for the lower and central parts of the right kidney and for the central part of the spleen. The analysis of the linear correlation coefficient revealed that the most statistically significant results were achieved for the mean ADC values of both kidneys, the ADC values of the central parts of both kidneys and the central parts of spleens (Table 6).

There was no area of measurement in the Bland-Altman plot that showed excellent repeatability (a Bland-Altman 
Table 6. Linear correlation coefficient values of ADC measurements obtained by 3 examiners

\begin{tabular}{|c|c|c|c|}
\hline Organ & $\begin{array}{c}\text { Radiologist } 1 \\
\text { vs } 2\end{array}$ & $\begin{array}{c}\text { Radiologist } 1 \\
\text { vs } 3\end{array}$ & $\begin{array}{c}\text { Radiologist } 2 \\
\text { vs } 3\end{array}$ \\
\hline \multirow{2}{*}{$\begin{array}{l}\text { Spleen - } \\
\text { upper part }\end{array}$} & $r=+0.662$ & $r=+0.352$ & $r=+0.207$ \\
\hline & $p<0.001$ & $p=0.035$ & $p=0.226$ \\
\hline \multirow{2}{*}{$\begin{array}{l}\text { Spleen - } \\
\text { central part }\end{array}$} & $r=+0.798$ & $r=+0.419$ & $r=+0.501$ \\
\hline & $p<0.001$ & $p=0.011$ & $p=0.002$ \\
\hline \multirow{2}{*}{$\begin{array}{l}\text { Spleen - } \\
\text { lower part }\end{array}$} & $r=+0.726$ & $r=+0.286$ & $r=+0.143$ \\
\hline & $p<0.001$ & $p=0.091$ & $p=0.404$ \\
\hline \multirow{2}{*}{$\begin{array}{l}\text { Spleen - } \\
\text { average value }\end{array}$} & $r=+0.782$ & $r=+0.159$ & $r=-0.011$ \\
\hline & $p<0.001$ & $p=0.354$ & $p=0.948$ \\
\hline \multirow{2}{*}{$\begin{array}{l}\text { Right kidney - } \\
\text { upper part }\end{array}$} & $r=+0.896$ & $r=+0.183$ & $r=+0.355$ \\
\hline & $p<0.001$ & $p=0.284$ & $p=0.034$ \\
\hline \multirow{2}{*}{$\begin{array}{l}\text { Right kidney - } \\
\text { central part }\end{array}$} & $r=+0.799$ & $r=+0.747$ & $r=+0.641$ \\
\hline & $p<0.001$ & $p<0.001$ & $p<0.001$ \\
\hline \multirow{2}{*}{$\begin{array}{l}\text { Right kidney - } \\
\text { lower part }\end{array}$} & $r=+0.783$ & $r=+0.385$ & $r=+0.514$ \\
\hline & $p<0.001$ & $p=0.021$ & $p=0.001$ \\
\hline \multirow{2}{*}{$\begin{array}{l}\text { Right kidney - } \\
\text { average value }\end{array}$} & $r=+0.873$ & $r=+0.618$ & $r=+0.715$ \\
\hline & $p<0.001$ & $p<0.001$ & $p<0.001$ \\
\hline \multirow{2}{*}{$\begin{array}{l}\text { Left kidney - } \\
\text { upper part }\end{array}$} & $r=+0.674$ & $r=+0.359$ & $r=+0.373$ \\
\hline & $p<0.001$ & $p=0.031$ & $p=0.025$ \\
\hline \multirow{2}{*}{$\begin{array}{l}\text { Left kidney - } \\
\text { central part }\end{array}$} & $r=+0.751$ & $r=+0.358$ & $r=+0.436$ \\
\hline & $p<0.001$ & $p=0.032$ & $p=0.008$ \\
\hline \multirow{2}{*}{$\begin{array}{l}\text { Left kidney - } \\
\text { lower part }\end{array}$} & $r=+0.539$ & $r=+0.550$ & $r=+0.528$ \\
\hline & $p=0.001$ & $p=0.001$ & $p=0.001$ \\
\hline \multirow{2}{*}{$\begin{array}{l}\text { Left kidney - } \\
\text { average value }\end{array}$} & $r=+0.800$ & $r=+0.494$ & $r=+0.503$ \\
\hline & $p<0.001$ & $p=0.002$ & $p=0.002$ \\
\hline
\end{tabular}

Correlation coefficient values significantly different than zero, with $\mathrm{p}<0.05$, are in bold.

coefficient less than 5\%) for all pairs of examiners. Considering all pairs of examiners, the best ADC measurement reproducibility was in the mean ADC values for the left kidney; the second best was in the ADC values for the lower part of the left kidney (Table 7).
Table 7. Bland-Altman coefficient values for ADC results obtained by 3 examiners

\begin{tabular}{|l|c|c|c|}
\hline \multicolumn{1}{|c|}{ Organ } & $\begin{array}{c}\text { Radiologist 1 } \\
\text { vs 2 }\end{array}$ & $\begin{array}{c}\text { Radiologist 1 } \\
\text { vs 3 }\end{array}$ & $\begin{array}{c}\text { Radiologist 2 } \\
\text { vs 3 }\end{array}$ \\
\hline $\begin{array}{l}\text { Spleen - } \\
\text { upper part } \\
\text { Spleen - } \\
\text { central part }\end{array}$ & $11.1 \%$ & $8.3 \%$ & $5.6 \%$ \\
\hline $\begin{array}{l}\text { Spleen - } \\
\text { lower part } \\
\text { Spleen - } \\
\text { average value }\end{array}$ & $5.6 \%$ & $11.1 \%$ & $8.3 \%$ \\
\hline $\begin{array}{l}\text { Right kidney - } \\
\text { upper part }\end{array}$ & $\mathbf{2 . 8 \%}$ & $5.6 \%$ & $5.6 \%$ \\
\hline $\begin{array}{l}\text { Right kidney - } \\
\text { middle part }\end{array}$ & $\mathbf{2 . 8 \%}$ & $5.6 \%$ & $8.3 \%$ \\
\hline $\begin{array}{l}\text { Right kidney - } \\
\text { lower part }\end{array}$ & $5.3 \%$ & $5.6 \%$ & $5.3 \%$ \\
\hline $\begin{array}{l}\text { Right kidney - } \\
\text { average value }\end{array}$ & $5.6 \%$ & $5.6 \%$ & $\mathbf{2 . 8} \%$ \\
\hline $\begin{array}{l}\text { Left kidney - } \\
\text { upper part } \\
\text { Left kidney - } \\
\text { central }\end{array}$ & $5.6 \%$ & $5.6 \%$ & $5.6 \%$ \\
\hline $\begin{array}{l}\text { Left kidney - } \\
\text { lower part }\end{array}$ & $5.6 \%$ & $5.6 \%$ & $5 \%$ \\
\hline $\begin{array}{l}\text { Left kidney - } \\
\text { average value }\end{array}$ & $5.6 \%$ & $5.6 \%$ & $5 \%$ \\
\hline
\end{tabular}

Results exceeding 5\% indicate poor reproducibility (in bold).

\section{Discussion}

The results of the statistical analysis in the present study confirm the findings of previous studies pointing out the limitations of the DWI technique and quantitative evaluation of water molecule diffusion using ADC maps. The analysis of the homogeneity of the diffusion in different organs revealed that the spleen may not be a good reference organ. It has been observed that ADC values in each part of the spleen differ significantly. As suggested by Hong et al., the renal cortex seems to be a more accurate area to perform reference measurements. ${ }^{11}$ In addition, in the current study, the analysis using Pearson's correlation test showed statistically significant reproducibility of ADC values in all parts of the left kidney, as well as in the central and lower parts of the right kidney. The Bland-Altman test also revealed significant reproducibility of ADC measurements for the kidneys, particularly the left kidney (the mean ADC value as well as the ADC value of the lower part). However, it is often the case that only the upper and central parts of the kidney are visible on echo planar images (EPI), which could make ADC measurement in the lower parts impossible. ${ }^{10}$ Due to the statistically significant reproducibility of ADC values in the Pearson's correlation test, the central part of the spleen should be also considered as a reference area. However, the present study included only healthy subjects without spleen pathologies. Patients with liver fi- 
brosis usually develop portal hypertension, causing splenomegaly, which can result in increased heterogeneity of the spleen parenchyma on ADC maps as well as changes in water diffusion. ${ }^{12}$

DW-MRI is a non-invasive technique of great usefulness in the detection and differentiation of pathological lesions in the whole body, including the abdomen. However, there are some limitations to this method. One of them is the lack of standardization in DWI sequence protocols (different b-values, different ways of creating ADC maps). ${ }^{5,13}$ Another drawback is the absence of explicit cut-off values for the evaluation of different pathologies. As the present study showed, overcoming all these limitations may prove to be very difficult. It seems that further technical improvements are required to maximize the usefulness of DWI sequences. Further studies on a larger group of patients and using various DWI protocols (including 3T MR or higher) should be performed to ascertain the best conditions for maximizing the reproducibility of ADC measurements.

\section{References}

1. Bilgili, MYK. Reproductibility of apparent diffusion coefficients measurements in diffusion-weighted MRI of the abdomen with different b values. Eur J Radiol. 2012; 81(9):2066-2068.

2. Johnston KC, Wagner DP, Wang XQ, et al. Validation of an acute ischemic stroke model does diffusion-weighted imaging lesion volume offer a clinically significant improvement in prediction of outcome? Stroke. 2007;38(6):1820-1825.

3. Roethke M, Blondin D, Schlemmer HP, Franiel T. PI-RADS classification: Structured reporting for MRI of the prostate. Rofo. 2013;185(3):253-261.

4. Partridge SC, McDonald ES. Diffusion weighted MRI of the breast: Protocol optimization, guidelines for interpretation, and potential clinical applications. MRI Clinics of North America 2013. In press. [PMC free article][PubMed].

5. Taouli B, Koh DM. Diffusion-weighted MR Imaging of the Liver 1 . Radiology. 2009; 254(1):47-66.

6. Lassel EA, Rao R, Schwenke C, Schoenberg SO, Michaely HJ. Diffusion-weighted imaging of focal renal lesions: A meta-analysis. Eur Radiol. 2014;24(1):241-249.

7. Filipe JP, Curvo-Semedo L, Casalta-Lopes J, Marques MC, CaseiroAlves F. Diffusion-weighted imaging of the liver: Usefulness of ADC values in the differential diagnosis of focal lesions and effect of ROI methods on ADC measurements. MAGMA. 2013;26(3):303-312.

8. Taouli B, Vilgrain V, Dumont E, Daire JL, Fan B, Menu Y. Evaluation of liver diffusion isotropy and characterization of focal hepatic lesions with two single-shot echo-planar MR imaging sequences: Prospective study in 66 patients. Radiology. 2003;226:71-78.

9. Aubé C, Racineux PX, Lebigot J, et al. Diagnosis and quantification of hepatic fibrosis with diffusion weighted MR imaging: Preliminary results [in French]. J Radiol. 2004;85:301-306.

10. El-Hariri M, Ali TFT, Hussien HI. Apparent diffusion coefficient (ADC) in liver fibrosis: Usefulness of normalized ADC using the spleen as reference organ. The Egyptian Journal of Radiology and Nuclear Medicine. 2013;44(3):441-451.

11. Hong $Y$, Shi $Y$, Liao W, et al. Relative ADC measurement for liver fibrosis diagnosis in chronic hepatitis B using spleen/renal cortex as the reference organs at 3 T. Clin Radiol. 2014:69(6):581-588.

12. Klasen J, Lanzman RS, Wittsack HJ, et al. Diffusion-weighted imaging (DWI) of the spleen in patients with liver cirrhosis and portal hypertension. Magn Reson Imaging. 2013;31(7):1092-1096.

13. Papanikolaou N, Gourtsoyianni S, Yarmenitis S, Maris T, Gourtsoyiannis N. Comparison between two-point and four-point methods for quantification of apparent diffusion coefficient of normal liver parenchyma and focal lesions. Value of normalization with spleen. Eur J Radiol. 2010;73(2):305-309. 